\title{
Substituição parcial do farelo de soja pela farinha de carne e ossos em dietas para juvenis de tilápia-do-nilo
}

\author{
Eduardo Gianini Abimorad(1), Daniela Castellani(1), Giovani Sampaio Gonçalves(1), Daiane Mompean Romera(1), \\ Fabiana Garcia $^{(1)}$ e Thiago Matias Torres do Nascimento(2)
}

\begin{abstract}
(1)Agência Paulista de Tecnologia dos Agronegócios, Instituto de Pesca, Centro Avançado de Pesquisa Tecnológica do Agronegócio do Pescado Continental, Rodovia Washington Luis, Km 445, Caixa Postal 1052, CEP 15025-970 São José do Rio Preto, SP, Brasil. E-mail: abimorad@apta.sp.gov.br, daniela.castellani@apta.sp.gov.br, gsgoncalves@pesca.sp.gov.br, daianemompean@apta.sp.gov.br, fgarcia@apta.sp.gov.br (2)Universidade Estadual Paulista, Faculdade de Ciências Agrárias e Veterinárias, Departamento de Zootecnia, Via de Acesso Prof. Paulo Donato Castellane, s/no, CEP 14884-900 Jaboticabal, SP, Brasil. E-mail: thiago_zoounesp@yahoo.com.br
\end{abstract}

Resumo - O objetivo deste trabalho foi avaliar os efeitos da substituição parcial do farelo de soja pela farinha de carne e ossos em dietas para juvenis de tilápia-do-nilo na digestibilidade, na saúde, no desempenho e no custo de arraçoamento. $\mathrm{O}$ experimento foi conduzido durante 14 semanas, com 400 juvenis $(4,9 \pm 0,6 \mathrm{~g})$ distribuídos ao acaso em 16 tanques. Os peixes foram alimentados com quatro dietas contendo $0,15,30 \mathrm{e}$ $45 \%$ de substituição da proteína do farelo de soja pela proteína da farinha de carne e ossos. Foram avaliados parâmetros de desempenho, digestibilidade, hematologia e custo de arraçoamento. Os melhores resultados para ganho em peso e conversão alimentar aparente foram observados com 40 e $32 \%$ de substituição, respectivamente. O menor custo de arraçoamento foi obtido com 30 e $45 \%$. Houve efeito linear decrescente dos coeficientes de digestibilidade aparente da proteína com o aumento nos níveis de farinha de carne e ossos. Os peixes alimentados com dietas contendo até $24 \%$ de substituição apresentam aumento da concentração de hemoglobina. A dieta com $32 \%$ de substituição da proteína do farelo de soja pela proteína da farinha de carne e ossos promove melhor conversão alimentar para tilápia-do-nilo.

Termos para indexação: Oreochromis niloticus, alimento alternativo, digestibilidade aparente, fontes proteicas, hematologia, nutrição.

\section{Partial replacement of soybean meal by meat and bone meal in diets for Nile tilapia juveniles}

\begin{abstract}
The objective of this work was to evaluate the effects of the partial replacement of soybean meal by meat and bone meal in diets for juvenile Nile tilapia on digestibility, health, performance, and feeding cost. The experiment was carried out for 14 weeks, with 400 juveniles $(4.9 \pm 0.6 \mathrm{~g})$ distributed randomly into 16 tanks. The fish were fed with four diets containing $0,15,30$, and $45 \%$ replacement of protein from soybean meal by protein from meat and bone meal. Performance parameters, digestibility, hematology, and feeding cost were evaluated. The best results for weight gain and apparent feed conversion were observed with 40 and $32 \%$ replacement, respectively. The lowest feeding cost was obtained with 30 and $45 \%$. There was a linear decrease in the apparent digestibility coefficients of protein with increasing levels of meat and bone meal. Fish fed diets containing up to $24 \%$ replacement show increase of hemoglobin concentration. The diet with $32 \%$ replacement of protein from soybean meal by protein from meat and bone meal promotes better feeding conversion for Nile tilapia.
\end{abstract}

Index terms: Oreochromis niloticus, alternative food, apparent digestibility, protein sources, hematology, nutrition.

\section{Introdução}

A produção de alimentos para aquacultura foi o segmento que mais cresceu nas últimas décadas, aproximadamente $12 \%$ ao ano, em relação aos demais setores da produção animal (Zani, 2013). A principal responsável por esse crescimento foi a tilapicultura, que representa $47 \%$ da produção de pescado continental (Brasil, 2011).
A substituição das fontes tradicionais de proteína por alimentos alternativos que forneçam proteína a baixo custo é essencial para o desenvolvimento da cadeia produtiva do pescado (Boscolo et al., 2004). Atualmente, o farelo de soja é a principal fonte proteica em dietas comerciais para peixes onívoros, em razão da sua disponibilidade e da sua alta qualidade comparada às farinhas de peixe, que estão cada vez

Pesq. agropec. bras., Brasília, v.49, n.11, p.836-843, nov. 2014

DOI: $10.1590 / \mathrm{S} 0100-204 X 2014001100002$ 
mais escassas, com elevado custo (Guimarães et al., 2008) e com procedência e qualidade duvidosas. Assim como a farinha de peixe, o farelo de soja também é uma commodity que vem acumulando altas de preço nos últimos anos.

A farinha de carne e ossos bovina é ingrediente alternativo para substituir a proteína do farelo de soja, por sua composição química e seu menor preço. Há grande variabilidade no conteúdo proteico e na composição de aminoácidos desse alimento, uma vez que a farinha de carne e ossos apresenta valores de proteína bruta entre 33,53 e $52,43 \%$ e extrato etéreo entre 12,88 e 14,71\% (Pozza et al., 2004). No mercado, esse alimento é padronizado com valores de proteína bruta que variam de 42 a $46 \%$, mais próximos dos de proteína bruta do farelo de soja (Furuya, 2010). A farinha de carne e ossos bovina tem sido largamente utilizada em dietas para peixes e geralmente atua como redutor nos custos de formulações. Entretanto, a inclusão de altos níveis deste ingrediente pode levar a problemas no processo de extrusão e, principalmente, no desempenho dos peixes, em virtude da baixa qualidade de seus nutrientes (Pezzato et al., 2002).

Uma ferramenta auxiliar no diagnóstico e na determinação da condição de saúde dos peixes é o estudo das variáveis hematológicas (Tavares-Dias \& Moraes, 2004). O sangue é o tecido mais dinâmico do organismo e altera-se de acordo com a dieta consumida (Araujo et al., 2011). A aplicação da hematologia em pesquisas em nutrição de animais, especialmente peixes, torna-se importante para avalições do estado nutricional e patológico, bem como para formação de um banco de dados frente à carência de informações (Barros et al., 2009). Ao se considerar a grande disponibilidade de farinha de carne e ossos bovina no Brasil, aliada a seu baixo custo, trabalhos que visam sua utilização em dietas para tilápia são oportunos. Apesar de a tilápia-do-nilo (Oreochromis niloticus) ser uma espécie amplamente estudada, ainda há a necessidade de avanços em programas nutricionais, que envolvam avaliações sobre a substituição de alimentos para otimização da relação benefício/custo e saúde animal (Furuya, 2010).

O objetivo deste trabalho foi avaliar os efeitos da substituição parcial do farelo de soja pela farinha de carne e ossos em dietas para juvenis de tilápia-do-nilo na digestibilidade, na saúde, no desempenho e no custo de arraçoamento.

\section{Material e Métodos}

O experimento foi conduzido no Laboratório de Aquicultura, do Polo Regional do Noroeste Paulista, da Agência Paulista de Tecnologia dos Agronegócios/ Secretaria de Agricultura e Abastecimento do Estado de São Paulo (Apta/SAA-SP), no Município de Votuporanga, no Estado de São Paulo $\left(20^{\circ} 27^{\prime} 38^{\prime \prime}\right.$, $50^{\circ} 3^{\prime} 58^{\prime \prime} \mathrm{W}$ ), no período de 18/3/2013 a 14/6/2013. Quatrocentos juvenis de tilápia-do-nilo revertidos, com

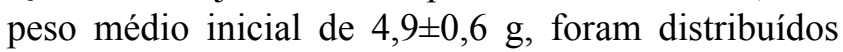
aleatoriamente em 16 tanques de $500 \mathrm{~L}$, na proporção de 25 peixes por tanque. O sistema era de recirculação de água, com taxa de renovação de aproximadamente quatro vezes ao dia, com filtragem mecânico-biológica e controle de temperatura. A água recolhida dos tanques convergia para uma caixa de decantação de matéria orgânica e passava por lãs acrílicas; em seguida, era distribuída em duas caixas de 500 L compostas de sistema de filtragem biológica tipo "dry-wet" e bombeada aos tanques.

Foi utilizado o delineamento inteiramente casualizado, em que 16 tanques receberam os quatro tratamentos dietéticos, que consistiram de $0,15,30$ e $45 \%$ de substituição da proteína do farelo de soja pela proteína da farinha de carne e ossos, com quatro repetições.

A temperatura, o oxigênio dissolvido e o $\mathrm{pH}$ da água do sistema de recirculação foram monitorados semanalmente. Para manter as condições ambientais adequadas durante o experimento, os tanques de alimentação e a caixa de decantação de matéria orgânica foram sifonados diariamente, com renovação de água de aproximadamente $10 \%$. Foi realizada a limpeza parcial do filtro mecânico, com renovação das lãs acrílicas. A temperatura da água do sistema foi mantida a $27,2 \pm 1,1^{\circ} \mathrm{C}$, por meio de resistência elétrica de $6000 \mathrm{~W}$ ligada a um termostato. Os valores médios de $\mathrm{pH}$ foram de $7,46 \pm 0,2$, e a concentração média de oxigênio dissolvido foi de 4,19 $\pm 1,4 \mathrm{mg} \mathrm{L}^{-1}$.

Foram formuladas quatro dietas isoproteicas a $30 \%$ de proteína bruta e isoenergéticas com 2.970 $\mathrm{kcal} \mathrm{kg}^{-1}$ de energia digestível, nas quais $0,15,30 \mathrm{e}$ $45 \%$ da proteína do farelo de soja foram substituídos pela proteína da farinha de carne e ossos (Tabela 1). Os ingredientes de cada dieta foram finamente moídos e misturados, e as rações foram extrusadas, com extrusora Ex Laboratório (Exteec, Ribeirão Preto, SP), em grânulos de 3 a 4 mm de diâmetro. Após a extrusão, 
as dietas foram secas em estufa com circulação de ar, a $50^{\circ} \mathrm{C}$, por 24 horas, e, para melhor conservação, foram colocadas em sacos de plástico etiquetados e armazenadas a $-20^{\circ} \mathrm{C}$. Durante o período experimental, os peixes foram alimentados diariamente, duas vezes ao dia, às $8 \mathrm{~h}$ e às $16 \mathrm{~h}$, até saciedade aparente.

Os mesmos peixes utilizados no ensaio de desempenho foram aproveitados para o ensaio de digestibilidade. Quando os peixes alcançaram aproximadamente $40 \mathrm{~g}$ de peso, eles passaram a ser alimentados com as dietas experimentais acrescidas de $1 \%$ de óxido de crômio-III $\left(\mathrm{Cr}_{2} \mathrm{O}_{3}\right)$, por sete dias. Após esse período, os peixes foram transferidos para os aquários de coleta de fezes.

Para a coleta de fezes, foi utilizado o sistema de Guelph modificado, que consiste em aquários

Tabela 1. Composição percentual e bromatológica das dietas experimentais, com diferentes níveis de substituição do farelo de soja pela farinha de carne e ossos, utilizadas na nutrição de juvenis de tilápia-do-nilo (Oreochromis niloticus).

\begin{tabular}{lcccc}
\hline Ingrediente & \multicolumn{4}{c}{ Nível de substituição (\%) } \\
\cline { 2 - 5 } & 0 & 15 & 30 & 45 \\
\hline Farelo de soja & 60,3 & 51,5 & 44,9 & 39,8 \\
Farinha de carne e ossos & 0,0 & 7,9 & 13,8 & 18,4 \\
Milho & 26,6 & 31,9 & 36,0 & 39,1 \\
Óleo de soja & 3,9 & 2,9 & 2,1 & 1,5 \\
Fosfato bicálcico & 6,1 & 3,5 & 1,5 & 0,0 \\
Calcário & 1,9 & 1,1 & 0,5 & 0,0 \\
Metionina & 0,20 & 0,22 & 0,24 & 0,25 \\
Suplemento vitamínico e mineral ${ }^{(1)}$ & 1,0 & 1,0 & 1,0 & 1,0 \\
\hline Composição analisada & & & & \\
$\quad$ Matéria seca (\%) & 88,7 & 88,8 & 88,9 & 89,0 \\
Proteína bruta (\%) & 30,2 & 29,8 & 31,2 & 31,4 \\
Proteína digestível (\%) & 26,3 & 25,3 & 26,4 & 24,6 \\
Extrato etéreo (\%) & 6,0 & 6,0 & 6,0 & 6,0 \\
Fibra bruta (\%) & 3,9 & 3,7 & 3,4 & 3,3 \\
Matéria mineral (\%) & 11,0 & 10,5 & 10,0 & 9,8 \\
Extrato não nitrogenado (\%) & 37,7 & 38,6 & 39,5 & 39,0 \\
Energia bruta (kcal kg-1) & 3.948 & 3.951 & 3.946 & 3.943 \\
Energia digestível (kcal kg $\left.{ }^{-1}\right)$ & 2.971 & 2.973 & 2.979 & 2.980 \\
\hline Preço (R\$ kg $\left.{ }^{-1}\right)$ & 1,21 & 1,18 & 1,12 & 1,09 \\
\hline
\end{tabular}

(1)Enriquecimento por kg de ração: 1.200 UI de vitamina A; 3.000 UI de vitamina $\mathrm{D} 3 ; 150 \mathrm{mg}$ de vitamina $\mathrm{E} ; 15 \mathrm{mg}$ de vitamina $\mathrm{K} ; 20 \mathrm{mg}$ de vitamina B1; $20 \mathrm{mg}$ de vitamina B2; 17,5 mg de vitamina B6; $40 \mathrm{mcg}$ de vitamina $\mathrm{B} 12 ; 300 \mathrm{mg}$ de vitamina $\mathrm{C} ; 6 \mathrm{mg}$ de ácido fólico; $50 \mathrm{mg}$ de ácido pantotênico; $1 \mathrm{mg}$ de biotina; $100 \mathrm{mg}$ de niacina; $500 \mathrm{mg}$ de colina; $125 \mathrm{mg}$ de inositol; 0,4 mg de cobalto; 17,5 mg de cobre; $100 \mathrm{mg}$ de ferro; $50 \mathrm{mg}$ de manganês; 0,8 mg de cálcio; 0,4 mg de sódio; $120 \mathrm{mg}$ de zinco; e $25 \mathrm{~g}$ de antioxidante. cilíndricos de fundo cônico $(80 \mathrm{~L})$, com tubo tipo Falcon acoplado à extremidade inferior; após a decantação das fezes dos peixes, um registro de esfera, localizado acima do tubo, era fechado e as fezes eram coletadas (Abimorad \& Carneiro, 2004). Os aquários de coleta de fezes foram abastecidos com água proveniente de poço artesiano e dotados com aeração e aquecedores para manter o oxigênio dissolvido e a temperatura desejada a $27^{\circ} \mathrm{C}$.

As fezes foram coletadas durante 10 horas. Para evitar a lixiviação de nutrientes, as fezes foram coletadas em intervalos de 1 hora e armazenadas em freezer a $-20^{\circ} \mathrm{C}$. Posteriormente, as amostras de fezes foram secas em estufa com circulação forçada de ar, a $55^{\circ} \mathrm{C}$, por 72 horas.

Após a realização da análise quantitativa do $\mathrm{Cr}_{2} \mathrm{O}_{3} \mathrm{e}$ dos nutrientes das dietas-teste e das fezes, o coeficiente de digestibilidade aparente (CDA) foi calculado por meio da fórmula (Nose, 1960):

$\mathrm{CDA}(\%)=100-100 \times\left[\left(\% \mathrm{Cr}_{2} \mathrm{O}_{3 \text { dieta }} / \% \mathrm{Cr}_{2} \mathrm{O}_{3 \text { fezes }}\right)\right.$

$\times\left(\%\right.$ Nutriente $_{\text {fezes }} / \%$ Nutriente $\left.\left._{\text {dieta }}\right)\right]$.

As análises de proteína dos ingredientes, das rações e das fezes, bem como as análises de composição corporal, foram realizadas no Laboratório de Nutrição de Organismos Aquáticos (Lanoa) do Centro de Aquicultura da Universidade Estadual Paulista (Caunesp), em Jaboticabal, SP, de acordo com as normas da AOAC (Latimer Junior, 2012). As concentrações de $\mathrm{Cr}_{2} \mathrm{O}_{3}$ das fezes e das rações foram determinadas por digestão nitroperclórica, conforme Furukawa \& Tsukahara (1966).

Foram avaliados o desempenho zootécnico e a retenção de proteína. Para isso, foram obtidos os seguintes parâmetros: ganho em peso, GPD = (peso $_{\text {final }}-$ peso $\left._{\text {inicial }}\right)$; conversão alimentar aparente, CAA $=$ consumo de alimento/ganho em peso; taxa de crescimento específico, TCE $=\left(\ln\right.$ peso $_{\text {final }}-$ $\ln$ peso $\left._{\text {inicial }}\right) \times 100 /$ tempo; e taxa de eficiência proteica, TEP $=$ ganho em peso/proteína bruta consumida .

No início do experimento, 20 juvenis da mesma população utilizada, foram mortos por aprofundamento em plano anestésico (benzocaína a $0,2 \mathrm{~g} \mathrm{~L}^{-1}$ ) e congelados para posterior determinação da composição corporal inicial da carcaça. No final do experimento, uma amostra de seis peixes de cada parcela, após jejum de 24 horas, também foi morta para posterior determinação da composição corporal final da carcaça 
e cálculo da retenção de proteína (RP), pela seguinte equação: $\mathrm{RP}=\left(\right.$ proteína $^{\text {corporal }} \mathrm{f}_{\text {final }} \times$ peso $\left._{\text {final }}\right)-$ $\left(\right.$ proteína corporal $_{\text {inicial }} \times$ peso $\left._{\text {inicial }}\right) \times 100 /$ consumo de proteína. A realização do experimento foi autorizada pelo Comitê de Ética em Experimentação Animal do Instituto de Pesca, do Centro Avançado de Pesquisa Tecnológica do Agronegócio do Pescado Continental, Protocolo $n^{\circ}$ 2/2014.7.

Para o cálculo dos custos, foram consideradas as cotações dos preços dos ingredientes em março de 2014 e a adição de $\mathrm{R} \$ 0,45$ por $\mathrm{kg}$, como custo de processamento (extrusão) e embalagem. As cotações dos preços e o adicional de processamento foram adquiridos junto à Raguife Indústria e Comércio de Rações (Santa Fé do Sul, SP). O custo de arraçoamento, dado em $\mathrm{R} \$$ por $\mathrm{kg}$ de peixes produzido, foi obtido por meio da multiplicação dos preços das dietas pela conversão alimentar aparente. $\mathrm{O}$ custo da proteína líquida, em $\mathrm{R} \$$ por $\mathrm{kg}$ de proteína retida na carcaça, foi calculado pelos preços da proteína das dietas dividido pelos valores de retenção de proteína. A proteína líquida representou o quanto da proteína consumida foi retida no animal, tendo-se descontado as perdas via fezes, urina, brânquias e incremento calórico (Rodehutscord et al., 1994).

No final do período experimental, uma alíquota de sangue de aproximadamente $1 \mathrm{~mL}$ foi colhida do vaso caudal de dois peixes de cada parcela (oito peixes por tratamento), com auxílio de seringas de plástico contendo anticoagulante (EDTA a 10\%). Para a determinação do percentual de hematócrito (Ht), utilizou-se centrifuga para micro-hematócrito. A contagem de células vermelhas (eritrócitos) foi realizada em câmera de Neubauer com diluição de $0,01 \%$ em solução de cloreto de sódio a $0,65 \%$, e as concentrações dehemoglobina $(\mathrm{Hb})$ foram determinadas por absorbância em $540 \mathrm{~nm}$ após reação com solução de cianeto de hemoglobina. Também foram calculadas as constantes corpusculares: volume corpuscular médio, $\mathrm{VCM}=\mathrm{Ht} \times 10$ /eritrócitos; hemoglobina corpuscular média, $\mathrm{HCM}=\mathrm{Hb} \times 10$ /eritrócitos; e concentração de hemoglobina corpuscular média, $\mathrm{CHCM}=\mathrm{Hb} / \mathrm{Ht}$ $\times 100$. As análises hematológicas foram realizadas no Laboratório de Enfermidades de Animais Aquáticos do Polo Regional do Noroeste Paulista e na Universidade Estadual Paulista, em Dracena, SP.

Os dados foram submetidos a análises de variância e regressão, a 5\% de probabilidade. A partir do estudo de regressão, foi determinado o ponto de máxima substituição do farelo de soja pela farinha de carne e ossos, calculado pela fórmula $\mathrm{P}_{\text {máx }}=\mathrm{a} / 2 \mathrm{~b}$, em que: a é o coeficiente linear e $b$ é o coeficiente quadrático da equação de regressão, a partir dos resultados de conversão alimentar aparente. Também foi estimada a magnitude relativa da digestibilidade da fração proteica da farinha de carne e ossos em relação à farinha de soja, por meio de regressão linear, conforme adaptado de Henn et al. (2006). Não foram aplicadas análises estatísticas para os parâmetros de valores monetários.

\section{Resultados e Discussão}

O ajuste quadrático dos dados de ganho em peso mostrou melhor resultado $\left(\mathrm{P}_{\text {máx }}\right)$ para $40 \%$ de substituição da proteína do farelo de soja pela proteína da farinha de carne e ossos; porém, houve efeito linear positivo para consumo de ração e, consequentemente, para consumo de proteína bruta (Tabela 2). Isso significa que o efeito dos níveis de substituição sobre o ganho em peso pode estar relacionado ao aumento no consumo, além de mostrar que o ganho em peso pode não ser apropriado para determinação do melhor nível de substituição. Entretanto, a inclusão de farinha de carne e ossos nas dietas indicou aumento na aceitabilidade das dietas, também relatado por Pereira-da-Silva \& Pezzato (2000).

A conversão alimentar aparente foi o parâmetro mais adequado para mostrar o efeito dos níveis de substituição dessas fontes proteicas (Figura 1). O ponto de mínima observado para esse parâmetro foi com $32 \%$ de substituição da proteína do farelo de soja pela proteína da farinha de carne e ossos (inclusão de $14,4 \%$ ), o que indicou melhoria significativa, quando comparado à ração sem adição de farinha de carne e ossos (Tabela 2). Uma provável explicação para esse resultado é o fato de que esse nível de inclusão de farinha de carne e ossos pode ter proporcionado melhor balanceamento de aminoácidos na dieta. Segundo Fasakin et al. (2005), a combinação de uma fonte de origem animal com uma de origem vegetal é uma forma de reduzir efeitos negativos do desbalanceamento de aminoácidos, problemas de digestibilidade e fatores antinutricionais resultantes do uso de apenas uma fonte de origem vegetal. Níveis de substituição semelhantes aos do presente trabalho também foram encontrados por Veiverberg et al. (2008), para juvenis de carpa 
capim (Ctenopharyngodon idella), que observaram melhores resultados de taxa de crescimento específico com $30 \%$ de substituição do farelo de soja pela farinha de carne e ossos.

Os menores custos de arraçoamento foram obtidos com 30 e $45 \%$ de substituição ( $\mathrm{R} \$ 1,25$ por $\mathrm{kg}$ de peixe), e os menores custos de proteína líquida foram observados com $45 \%$ de substituição ( $\mathrm{R} \$ 6,84$ por $\mathrm{kg}$ de proteína retida) da proteína do farelo de soja pela proteína da farinha de carne e ossos (Tabela 2).

Ao se considerar a diferença de preço por $\mathrm{kg}$ de até R\$ 0,12 entre a dieta sem farinha de carne e ossos ( $\mathrm{R} \$ 1,21)$ e a com $45 \%$ de substituição ( $\mathrm{R} \$ 1,09)$, sem prejuízo significativo na retenção de proteína na carcaça (Tabela 2), a melhor opção é utilizar a dieta com $45 \%$ de substituição do farelo de soja pela farinha de carne e ossos, para obtenção de menor custo de proteína líquida. Contudo, o aumento do nitrogênio excretado ou utilizado como incremento calórico pode ser proporcional ao aumento de consumo de proteína observado em função do acréscimo nos níveis de substituição (efeito linear), o que pode tornar-se um risco para o ambiente. Abimorad et al. (2009) constataram menor excreção de $\mathrm{N}$ por juvenis de pacu (Piaractus mesopotamicus) alimentados com dietas contendo $23 \%$ de proteína digestível em relação àqueles alimentados com dietas com $30 \%$ de proteína digestível. Botaro et al. (2007) também verificaram menor excreção de $\mathrm{N}$ por tilápia-do-nilo alimentada com dieta contendo menos que $24,9 \%$ de proteína digestível. Assim, a possível excreção de $\mathrm{N}$ deve ser um risco ambiental a ser considerado na escolha do nível de substituição de proteína mais adequado.

Para os coeficientes de digestibilidade aparente da fração proteica, houve efeito linear negativo em relação ao acréscimo da farinha de carne e ossos, ao se substituir o farelo de soja (Tabela 3). Não foram observadas diferenças entre as concentrações de proteína digestível das dietas experimentais. De acordo com Henn et al. (2006), é possível estimar o coeficiente de digestibilidade aparente da proteína da fonte proteica adicionada, pela inclinação da reta em ajuste linear, o qual é dado pelo valor de "a" da equação: $y=a x+b$. Como, no presente trabalho, não houve inclusão de fonte proteica e sim substituição, a inclinação da reta obtida não representou o coeficiente de digestibilidade da proteína da farinha de carne e ossos, mas o quanto sua digestibilidade foi menor em relação a do farelo de soja (Figura 2). Esse tipo de abordagem é ferramenta importante para estimar a magnitude relativa da digestibilidade de ingredientes em estudos de substituição de fontes alimentares. Allan et al. (2000), ao avaliar juvenis de perca prateada (Bidyanus bidyanus), também observaram menor digestibilidade da fração proteica da farinha de carne e ossos em relação ao farelo de soja, de aproximadamente $23,3 \%$. Esses autores relacionaram essa redução à baixa digestibilidade da lisina desse ingrediente, em razão do tipo de processamento utilizado em sua fabricação. Pezzato et al. (2002) também encontraram menores valores de digestibilidade da fração proteica da farinha de carne $(73,19 \%)$ em comparação aos do farelo de soja $(91,56 \%)$ para juvenis de tilápia-do-nilo.

Tabela 2. Desempenho zootécnico, retenção de proteína bruta, custos de arraçoamento e da proteína líquida de juvenis de tilápia-do-nilo (Oreochromis niloticus) alimentados com dietas experimentais contendo diferentes níveis de substituição do farelo de soja pela farinha de carne e $\operatorname{ossos}^{(1)}$.

\begin{tabular}{|c|c|c|c|c|c|}
\hline \multirow[t]{2}{*}{ Variável } & \multicolumn{4}{|c|}{ Nível de substituição (\%) } & \multirow[t]{2}{*}{ Valor de $\mathrm{p}$} \\
\hline & 0 & 15 & 30 & 45 & \\
\hline Ganho em peso $(g)^{(2)}$ & $72,41 \pm 1,7$ & $77,28 \pm 2,4$ & $83,65 \pm 3,7$ & $82,33 \pm 2,5$ & $0,0008 * *$ \\
\hline Consumo de ração $(\mathrm{g})^{(3)}$ & $86,88 \pm 1,1$ & $89,46 \pm 0,9$ & $93,12 \pm 2,4$ & $94.13 \pm 3,1$ & $0,0197^{*}$ \\
\hline Consumo de proteína bruta $(\mathrm{g})^{(4)}$ & $26,23 \pm 0,4$ & $26,59 \pm 0,3$ & $29,16 \pm 0,8$ & $29,51 \pm 1,0$ & $<0,0001 *$ \\
\hline Conversão alimentar aparente ${ }^{(5)}$ & $1,20 \pm 0,03$ & $1,16 \pm 0,04$ & $1,11 \pm 0,03$ & $1,14 \pm 0,01$ & $0,0280^{*}$ \\
\hline Eficiência de retenção de proteína bruta $(\%)^{(6)}$ & $52,63 \pm 0,6$ & $53,22 \pm 1,6$ & $51,00 \pm 2,0$ & $50,60 \pm 1,0$ & $0,0573^{\mathrm{ns}}$ \\
\hline Custo de arraçoamento ( $\mathrm{R} \$$ por $\mathrm{kg})$ & $1,47 \pm 0,04$ & $1,37 \pm 0,05$ & $1,25 \pm 0,03$ & $1,25 \pm 0,01$ & - \\
\hline Custo da proteína líquida ( $\mathrm{R} \$$ por $\mathrm{kg}$ ) & $7,60 \pm 0,09$ & $7,43 \pm 0,23$ & $7,05 \pm 0,27$ & $6,84 \pm 0,14$ & - \\
\hline
\end{tabular}

${ }^{(1)}$ Médias \pm desvio-padrão, $\mathrm{n}=4 .{ }^{(2)}$ Efeito quadrático: $\mathrm{y}=71,806+56,108 \mathrm{x}-70,505 \mathrm{x}^{2}, \mathrm{R}^{2}=0,72 .{ }^{(3)}$ Efeito linear: $\mathrm{y}=87,131+16,817 \mathrm{x}, \mathrm{R}^{2}=0,67 .{ }^{(4)} \mathrm{Efeito} \mathrm{linear:}$ $\mathrm{y}=25,963+8,4075 \mathrm{x}, \mathrm{R}^{2}=0,76 .{ }^{(5)}$ Efeito quadrático: $\mathrm{y}=1,2054-0,5075 \mathrm{x}+0,8031 \mathrm{x}^{2}, \mathrm{R}^{2}=0,50$. ${ }^{\left({ }^{6}\right)}$ Retenção de proteína $=\left(\right.$ proteína corporal $_{\text {final }} \times$ peso $\left._{\text {final }}\right)$ - $\left(\right.$ proteína corporal $_{\text {inicial }} \times$ peso $\left._{\text {inicial }}\right) /$ consumo de proteína bruta $\times 100$. ns Não significativo. * e **Significativo a 5 e $1 \%$ de probabilidade, respectivamente. 
Não houve diferença significativa entre as dietas para hematócrito, eritrócitos, volume corpuscular médio, hemoglobina corpuscular média e concentração de hemoglobina corpuscular média (Tabela 3). $\mathrm{O}$ número de eritrócitos e os valores de hematócrito foram semelhantes aos descritos por Azevedo et al. (2006), que avaliaram os parâmetros hematológicos de tilápias-do-nilo parasitadas ou não, oriundas de pisciculturas do Estado de Santa Catarina. Apesar das diferentes condições de cultivo entre os estudos, a comparação torna-se importante pela carência de valores referência para os dados hematológicos de peixes disponíveis na literatura.

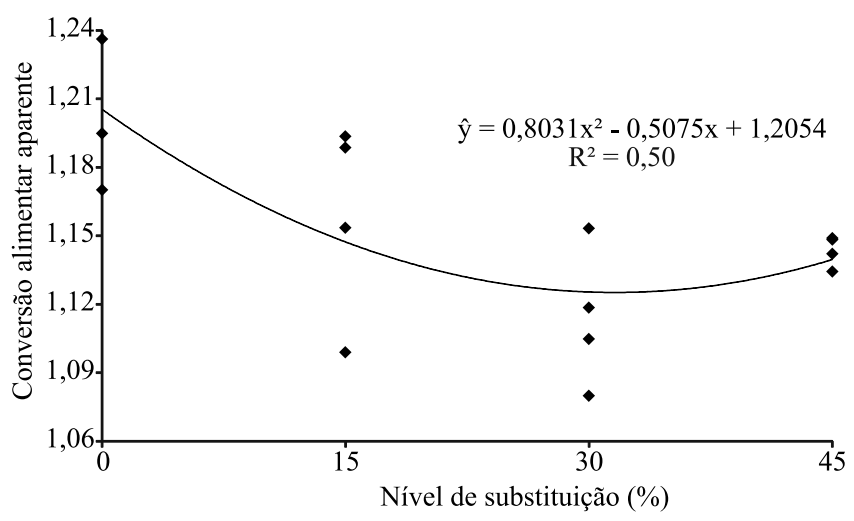

Figura 1. Conversão alimentar aparente de juvenis de tilápia-do-nilo (Oreochromis niloticus) alimentados com dietas experimentais contendo diferentes níveis de substituição do farelo de soja pela farinha de carne e ossos.
Houve efeito quadrático para concentração de hemoglobina. Os resultados $\left(\mathrm{P}_{\text {máx }}\right)$ são indicativos de que os peixes alimentados com dietas contendo até $24 \%$ de substituição da proteína do farelo de soja pela da farinha de carne e ossos (inclusão de $11,5 \%$ ) apresentaram aumento na concentração de hemoglobina no sangue. Como o ferro faz parte da composição da hemoglobina, a variação em sua concentração no sangue das tilápias-do-nilo avaliadas no presente trabalho pode ser atribuída à presença do ferro proveniente da farinha de carne e ossos. Embora haja variação na composição das farinhas de carne e ossos, de modo geral, estas apresentam elevado teor de ferro (Forster et al., 2003). Shiau \& Su (2003) avaliaram a inclusão de níveis crescentes de ferro na dieta de juvenis de tilápia e verificaram que a inclusão de até $400 \mathrm{mg} \mathrm{kg}^{-1}$ de ração aumenta a concentração de hemoglobina e os valores de hematócrito. Contudo, no presente trabalho, notou-se que a inclusão de valores superiores a $11,5 \%$ de farinha de carne e ossos na dieta reduziu a concentração de hemoglobina. Isso pode estar associado a um possível excesso de ferro nessas dietas, uma vez que o enriquecimento de ferro por meio do suplemento vitamínico mineral foi de $100 \mathrm{mg} \mathrm{kg}^{-1}$ na ração (Tabela 1). Segundo Barros et al. (2004), o excesso de ferro dietético pode causar prejuízo no crescimento e alterações hepáticas em peixes. Dessa forma, de acordo com os resultados obtidos, a farinha de carne e ossos também pode ser considerada como fonte de ferro para juvenis de tilápia-do-nilo, ao promover aumento da concentração de hemoglobina com inclusão de até $11,5 \%$ na dieta.

Tabela 3. Coeficientes de digestibilidade aparente de proteína bruta (CDA PB), proteína digestível e variáveis hematológicas (série vermelha) de juvenis de tilápia-do-nilo (Oreochromis niloticus) alimentados com dietas experimentais contendo diferentes níveis de substituição do farelo de soja pela farinha de carne e ossos ${ }^{(1)}$.

\begin{tabular}{lccccc}
\hline Parâmetro & \multicolumn{3}{c}{ Nível de substituição (\%) } & \multicolumn{2}{c}{ Valor de p } \\
\cline { 2 - 5 } & 0 & 15 & 30 & 45 & $0,0251^{*}$ \\
CDA PB (\%) $(2)$ & $87,05 \pm 0,38$ & $85,08 \pm 0,88$ & $84,42 \pm 3,75$ & $78,57 \pm 5,63$ & $0,1243^{\text {ns }}$ \\
Proteína digestível (\%) & $26,28 \pm 0,12$ & $25,29 \pm 0,26$ & $26,43 \pm 1,17$ & $24,63 \pm 1,77$ & $0,2583^{\text {ns }}$ \\
Hematócrito (\%) & $30,9 \pm 3,5$ & $34,5 \pm 3,3$ & $32,1 \pm 3,0$ & $33,3 \pm 4,7$ & $0,1567^{\text {ns }}$ \\
Eritrócitos $\left(10^{6} \mu \mathrm{L}^{-1}\right)$ & $0,84 \pm 0,3$ & $1,03 \pm 0,2$ & $1,11 \pm 0,3$ & $0,81 \pm 0,3$ & $0,0015^{* *}$ \\
Hemoglobina $\left(\mathrm{g} \mathrm{dL}^{-1}\right)^{(3)}$ & $8,10 \pm 0,3$ & $9,21 \pm 0,7$ & $9,15 \pm 0,6$ & $8,65 \pm 0,5$ & $0,1229^{\text {ns }}$ \\
Volume corpuscular médio (fL) & $419,7 \pm 173$ & $350,3 \pm 87$ & $311,3 \pm 86$ & $521,0 \pm 303$ & $0,2602^{\text {ns }}$ \\
Hemoglobina corpuscular média (pg cel $\left.{ }^{-1}\right)$ & $109,8 \pm 44$ & $93,6 \pm 23$ & $88,9 \pm 24$ & $136,3 \pm 85$ & $0,2736^{\text {ns }}$ \\
CHCM $^{(4)}\left(\mathrm{g} \mathrm{dL}^{-1}\right)$ & $26,5 \pm 2,8$ & $26,8 \pm 2,8$ & $28,6 \pm 1,9$ & $26,3 \pm 2,5$ & \\
\hline
\end{tabular}

${ }^{(1)}$ Médias \pm desvio-padrão, $n=4$. ${ }^{(2)}$ Efeito linear: $\mathrm{y}=87,642-0,1773 \mathrm{x}, \mathrm{R}^{2}=0,49 .{ }^{(3)}$ Efeito quadrático: $\mathrm{y}=8,2699+8,4641 \mathrm{x}-17,713 \mathrm{x}^{2}, \mathrm{R}^{2}=0,33 .\left(\mathrm{P}_{\mathrm{max}}=24 \%\right)$. ${ }^{(4)} \mathrm{CHCM}$, concentração de hemoglobina corpuscular média. nsNão significativo. * e **Significativo a 5 e $1 \%$ de probabilidade, respectivamente. 


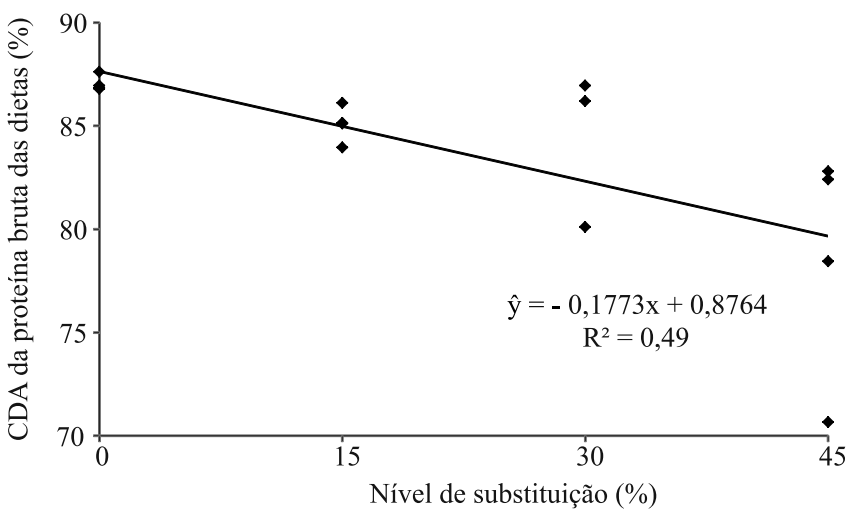

Figura 2. Coeficiente de digestibilidade aparente (CDA) da fração proteica para juvenis de tilápia-do-nilo (Oreochromis niloticus) alimentados com dietas experimentais contendo diferentes níveis de substituição do farelo de soja pela farinha de carne e ossos.

\section{Conclusões}

1. A substituição de até $24 \%$ da proteína do farelo de soja pela proteína da farinha de carne e ossos aumenta a concentração de hemoglobina em juvenis de tilápia-do-nilo (Oreochromis niloticus).

2. A substituição de $32 \%$ da proteína do farelo de soja pela proteína da farinha de carne e ossos promove melhor custo de arraçoamento e conversão alimentar aparente por juvenis de tilápia-do-nilo.

3. Em juvenis de tilápia-do-nilo, a digestibilidade da proteína da farinha de carne e ossos é menor que a do farelo de soja.

\section{Agradecimentos}

À Raguife Indústria e Comércio de Rações, pela doação dos ingredientes para compor as dietas experimentais; à Piscicultura Peixe Vivo, pela doação dos alevinos revertidos de tilápia-do-nilo; e ao Prof. Dr. Leonardo Takahashi da Universidade Estadual Paulista, pelo auxílio nas análises de hemoglobina.

\section{Referências}

ABIMORAD, E.G.; CARNEIRO, D.J. Métodos de coleta de fezes e determinação dos coeficientes de digestibilidade da fração protéica e da energia dos alimentos para o pacu, Piaractus mesopotamicus (Holmberg, 1887). Revista Brasileira de Zootecnia, v.33, p.1101-1109, 2004. DOI: 10.1590/S1516-35982004000500001.
ABIMORAD, E.G.; FAVERO, G.C.; CASTELLANI, D.; GARCIA, F.; CARNEIRO, D.J. Dietary supplementation of lysine and/or methionine on performance, nitrogen retention and excretion in pacu Piaractus mesopotamicus reared in cages. Aquaculture, v.295, p.266-270, 2009. DOI: 10.1016/j.aquaculture.2009.07.001.

ALLAN, G.L.; PARKINSON, S.; BOOTH, M.A.; STONE, D.A.J.; ROWLAND, S.J.; FRANCES, J.; WARNER-SMITH, R. Replacement of fish meal in diets for Australian silver perch, Bidyanus bidyanus: I. Digestibility of alternative ingredients. Aquaculture, v.186, p.293-310, 2000. DOI: 10.1016/ S0044-8486(99)00380-4.

ARAUJO, D. de M.; PEZZATO, A.C.; BARROS, M.M.; PEZZATO, L.E.; NAKAGOME, F.K. Hematologia de tilápias-do-nilo alimentadas com dietas com óleos vegetais e estimuladas pelo frio. Pesquisa Agropecuária Brasileira, v.46, p.294-302, 2011. DOI: 10.1590/S0100-204X2011000300010.

AZEVEDO, T.M.P. de; MARTINS, M.L.; BOZZO, F.R.; MORAES, F.R. de. Haematological and gill responses in parasitized tilapia from Valley of Tijucas River, SC, Brazil. Scientia Agricola, v.63, p.115-120, 2006. DOI: 10.1590/S0103-90162006000200002.

BARROS, M.M.; PEZZATO, L.E.; HISANO, H.; FALCON, D.R.; SÁ, M.V. do C. Farinha de sangue tostada e dietas práticas para tilápia do Nilo (Oreochromis niloticus L.). Acta Scientiarum. Animal Sciences, v.26, p.5-13, 2004. DOI: 10.4025/actascianimsci. v26i1.1895.

BARROS, M.M.; RANZANI-PAIVA, M.J.T.; PEZZATO, L.E.; FALCON, D.R.; GUIMARÃES, I.G. Haematological response and growth performance of Nile tilapia (Oreochromis niloticus L.) fed diets containing folic acid. Aquaculture Research, v.40, p.895-903, 2009. DOI: 10.1111/j.1365-2109.2009.02175.x.

BOSCOLO, W.R.; HAYASHI, C.; MEURER, F.; FEIDEN, A.; BOMBARDELLI, R.A. Digestibilidade aparente da energia e proteína das farinhas de resíduo da filetagem da tilápia do Nilo (Oreochromis niloticus) e da corvina (Plagioscion squamosissimus) e farinha integral do camarão canela (Macrobrachium amazonicum) para a tilápia do Nilo. Revista Brasileira de Zootecnia, v.33, p.8-13, 2004. DOI: 10.1590/S1516-35982004000100002.

BOTARO, D.; FURUYA, W.M.; SILVA, L.C.R.; SANTOS, L.D. dos; SILVA, T.S. de C.; SANTOS, V.G. dos. Redução da proteína da dieta com base no conceito de proteína ideal para tilápias-do-nilo (Oreochromis niloticus) criadas em tanques-rede. Revista Brasileira de Zootecnia, v.36, p.517-525, 2007. DOI: 10.1590/ S1516-35982007000300001.

BRASIL. Ministério da Pesca e Aquicultura. Boletim estatístico da pesca e aquicultura 2011. Brasília: MPA, 2011. 60p. Disponível em: <http://www.mpa.gov.br>. Acesso em: 25 set. 2014.

FASAKIN, E.A.; SERWATA, R.D.; DAVIES, S.J. Comparative utilization of rendered animal derived products with or without composite mixture of soybean meal in hybrid tilapia (Oreochromis niloticus x Oreochromis mossambicus) diets. Aquaculture, v.249, p.329-338, 2005. DOI:10.1016/j.aquaculture.2005.02.059.

FORSTER, I.P.; DOMINY, W.; OBALDO, L.; TACON, A.G.J. Rendered meat and bone meals as ingredients of diets for shrimp Litopenaeus vannamei (Boone, 1931). Aquaculture, v.219, p.655-670, 2003. DOI: 10.1016/S0044-8486(02)00457-X. 
FURUKAWA, A.; TSUKAHARA, H. On the acid digestion for the determination of chromic oxide as an index substance in the study of digestibility of fish feed. Bulletin of the Japanese Society Fisheries, v.32, p.502-506, 1966. DOI: 10.2331/suisan.32.502.

FURUYA, W.M. Tabelas brasileiras para a nutrição de tilápias. Toledo: GFM, 2010. 100p.

GUIMARÃES, I.G.; PEZZATO, L.E.; BARROS, M.M.; TACHIBANA, L. Nutrient digestibility of cereal grain products and by-products in extruded diets for Nile tilapia. Journal of the World Aquaculture Society, v.39, p.781-789, 2008. DOI: 10.1111/j.1749-7345.2008.00214.x.

HENN, J.D.; RIBEIRO, A.M.L.; KESSLER, A. de M. Comparação do valor nutritivo de farinhas de sangue e de farinhas de vísceras para suínos utilizando-se o método da proteína e gordura digestíveis e o método de substituição. Revista Brasileira de Zootecnia, v.35, p.1366-1372, 2006. DOI: 10.1590/S1516-35982006000500016.

LATIMER JUNIOR, G.W. Official methods of analysis of AOAC International. $19^{\text {th }}$ ed. Washington: AOAC International, 2012.

NOSE, T. On the digestion of food protein by gold-fish (Carassius auratus L.) and rainbow trout (Salmo irideus G.). Bulletin of Freshwater Fisheries Research Laboratory, v.10, p.11-22, 1960.

PEREIRA-DA-SILVA, E.M.; PEZZATO, E.L. Respostas da tilápia do Nilo (Oreochromis niloticus) à atratividade e palatabilidade de ingredientes utilizados na alimentação de peixes. Revista Brasileira de Zootecnia, v.29, p.1273-1280, 2000. DOI: 10.1590/ S1516-35982000000500003.

PEZZATO, L.E.; MIRANDA, E.C. de; BARROS, M.M.; PINTO, L.G.Q.; FURUYA, W.M.; PEZZATO, A.C. Digestibilidade aparente de ingredientes pela tilápia do Nilo (Oreochromis niloticus). Revista Brasileira de Zootecnia, v.31, p.1595-1604, 2002. DOI: 10.1590/S0100-204X2013001200001.

POZZA, P.C.; GOMES, P.C.; DONZELE, J.L.; ROSTAGNO, H.S.; POZZA, M.S. dos S.; NOGUEIRA, E.T. Digestibilidade ideal aparente e verdadeira de aminoácidos de farinhas de carne e ossos para suínos. Revista Brasileira de Zootecnia, v.33, p.1181-1191, 2004. DOI: 10.1590/S1516-35982004000500010.

RODEHUTSCORD, M.; MANDEL, S.; PFEFFER, E. Reduced protein content and use of wheat gluten in diets for rainbow trout: effects on water loading with $\mathrm{N}$ and P. Journal of Applied Ichthyology, v.10, p.271-273, 1994. DOI: 10.1111/ j.1439-0426.1994.tb00166.x.

SHIAU, S.; SU, L.W. Ferric citrate is half as effective as ferrous sulfate in meeting the iron requirement of juvenile tilapia, Oreochromis niloticus x O. aureus. Journal of Nutrition, v.133, p.483-488, 2003.

TAVARES-DIAS, M.; MORAES, F.R. de. Hematologia de peixes teleósteos. Ribeirão Preto: Villimpress, 2004. 144p.

VEIVERBERG, C.A.; BERGAMIN, G.T.; RADÜNZ NETO, J.; LAZZARI, R.; CORRÊIA, V.; ROSSATO, S.; SUTILI, F.J.; FERREIRA, C.C. Farelo de soja como substituto à farinha de carne e ossos em dietas para juvenis de carpa capim Ctenopharyngodon idella. Boletim do Instituto de Pesca, v.34, p.463-472, 2008.

ZANI, A. Alimentação animal não recupera perdas acumuladas no ano passado. Cerqueira César: Sindirações, 2013. 6p. (Boletim Informativo do Setor de Alimentação Animal. Dezembro/2013). Disponível em: <http://sindiracoes.org.br/wp-content/ uploads/2013/12/sindiracoes-boletim_dezembro_05122013_site. pdf>. Acesso em: 29 set. 2014.

$\overline{\text { Recebido em } 15 \text { de abril de } 2014 \text { e aprovado em } 29 \text { de outubro de } 2014}$ 